Research Article

\title{
Case Study on BIM and Value Engineering Integration for Construction Cost Control
}

\author{
Xiaojuan Li, ${ }^{1}$ Chen Wang $\mathbb{D}^{2},{ }^{2}$ and Ali Alashwal ${ }^{3}$ \\ ${ }^{1}$ College of Transportation and Civil Engineering, Fujian Agriculture and Forestry University, Fuzhou, Fujian Province, China \\ ${ }^{2}$ Higher-educational Engineering Research Centre for Intelligence and Automation in Construction of Fujian Province, \\ College of Civil Engineering, Huaqiao University, Xiamen, China \\ ${ }^{3}$ School of Built Environment, Western Sydney University, Penrith, NSW 2751, Australia \\ Correspondence should be addressed to Chen Wang; derekisleon@gmail.com
}

Received 28 September 2020; Revised 12 January 2021; Accepted 25 January 2021; Published 4 February 2021

Academic Editor: Jian Ji

Copyright (C) 2021 Xiaojuan Li et al. This is an open access article distributed under the Creative Commons Attribution License, which permits unrestricted use, distribution, and reproduction in any medium, provided the original work is properly cited.

\begin{abstract}
Construction projects consume a considerable amount of resources and funding. Cost control is an essential process to attain project success and enhance its value. Many studies have been dedicated to studying how value engineering (VE) can be used to control construction costs. However, limited studies can be found on the integration of building information modelling (BIM) and VE for better cost control and optimization. The main purpose of this study is to determine how BIM can be integrated with VE and illustrate the benefits of this integration. The study proposed a framework based on the analytic hierarchy process (AHP) and the entropy method to calculate the weight and coefficient. A case study method of a high-rise building project in China was used to validate the framework and demonstrate how BIM can be integrated with VE. The data were collected through document analysis, interviews, and a questionnaire survey targeted on project participants. The findings show that the integration of BIM in VE facilitates design modification and information extraction such as cost data. Using this approach showed a saving of $10 \%$ in project cost and duration. Besides, the overall quality and performance of the project have been enhanced. The findings show the significance of integrating BIM and VE to enhance building project functionality and performance before, during, and after the construction stage. This study contributes to providing empirical evidence of the advantages of this integrated approach including a better understanding of project components and requirements, easy access to project data, comprehensive weight and function analysis, easy validation of recommended solutions, and ability to virtually evaluate design changes and construction site planning.
\end{abstract}

\section{Introduction}

Regardless of the rapid development of technology and digitalization in this era, construction projects are still facing many fundamental issues such as project delay, cost overrun, and low efficiency and performance $[1,2]$. The construction industry in China, and many other countries, has been criticized to have many participants, long project cycle, high risk and uncertainty, lack of coordination among construction players, and lack of data sharing and resource integration $[3,4]$. In today's construction industry where the market is becoming saturated and the economic situation is grim, most construction companies are facing a survival crisis $[2,5,6]$. If a construction company wants to gain an advantage in the fierce market competition, it has to reduce the cost of the company to the greatest extent on the premise of ensuring certain construction quality and service. Similarly, clients are always looking for a product that has the highest value with the lowest possible cost. As construction projects consume a large sum of resources and investment funds, cost control is becoming one of the main criteria to determine their success.

Value engineering (VE) is one of the common cost control methods used in construction and other sectors such as manufacturing. VE can provide alternative solutions with the optimum cost to enhance project value, functionality, and performance. In the 1970s, VE was introduced in China, and the first VE standard was formulated in 1987. 
Subsequently, the establishment of the Value Engineering Committee of the Technical and Economic Research Society in 2005 contributed to increasing the application of this methodology. Since then, VE has been applied in construction projects and beyond to include products and processes of different sectors such as manufacturing. However, the construction sector has not realized the full potentials of VE. Many factors affect the cost of construction projects, which increases the difficulty of cost control and management [4]. The application of VE in building projects remains limited due to the large scale of the project leading to too much information, making it difficult to carry out value engineering; the long life cycle of the building and the increase in risk factors are not conducive to the development of value engineering [7]. Therefore, the application of VE alone is not sufficient for effective cost control and management.

Building information modelling (BIM) has been widely applied in construction due to several advantages including reducing project execution time, integration of functions and professionals, efficiency through clash detection and avoidance, and reduction of risk $[4,5,8]$. Specifically, BIM has the potential to enhance the practice of $\mathrm{VE}$ in many aspects [8]. For example, the three-dimensional (3D) visualization can be useful for the VE team to better understand the design and building components. Information extraction and design modification, which are integral processes of VE, can be conducted in BIM easily. Previous studies on the integration of VE and BIM remain limited, and there is no empirical evidence to show the perceived benefits of this integration. VE workshops conducted to evaluate the project or design are time-consuming and require a large amount of information and data from different stakeholders of the project. Usually, the proposed changes to the project or design cannot be tested immediately and have to be sent to the client or the architect first for approval. Therefore, the purpose of this study is to determine how VE can be integrated with BIM and highlight the benefits of this integration based on an actual case study of a high-rise building construction in China. The following section provides a review of previous studies on the application of BIM for cost management and the integration of VE and BIM.

\section{VE and BIM Integrated Framework}

Value engineering (VE), which is also known as value analysis, was developed in the manufacturing sector to overcome the shortage of resources after the Second World War. VE can be defined as a systematic approach to providing the necessary functions and quality, while eliminating unnecessary costs [9]. The value of a project or element can be judged based on the ratio between the function and cost. $\mathrm{VE}$ involves the conducting of one or several workshops (also called value study) to understand the project, analyze its components and function, explore issues such as nonvalue elements, develop ideas and alternatives, select the appropriate alternatives, and implementation and audit. The team size in the value study ranged between six to eight experts including a facilitator or a leader [9]. VE has several applications within construction projects such as functional analysis and cost control of construction elements and materials $[5,6]$. Other applications of VE include evaluating the functionality and cost of new highway projects [10] and evaluating green residential buildings to save the construction and energy cost [11].

BIM has been most commonly used for $3 \mathrm{D}$ visualization, automation of documentation, and clash detection. The most important benefits of BIM included better marketing and a clearer understanding of projects which is crucial for clients [12]. Other studies investigated the application of BIM for cost management alongside other aspects such as time and quality [13-16]. BIM has been gradually applied to various fields of construction projects, providing strong support for the smooth development of construction projects [17]. BIM has also been used for cost control as it provides several advantages related to cost management processes such as direct engineering cost, project change cost, measurement of cost, and dynamic cost monitoring [18].

Concerning BIM and VE integration, some studies can be found in the literature. Nath et al. [19] proposed a BIMbased workflow for the reengineering of the process of shop drawings generation. They applied this method to an element of the building (i.e., window) and focused on how this method can enhance productivity. Wei and Chen [20] claimed to use BIM and VE to improve the green building design. The study used simulation to develop different alternatives to the building envelop for optimum energy consumption. However, the study did not show how VE is being applied to enhance the design or choose a suitable alternative. Park et al. [21] focused on the creativity phase of a value engineering workshop and developed a BIM-based prototype to facilitate the generation and retrieval of ideas. The BIM-based idea bank can improve the efficiency of VE workshops. Based on this overview of the available literature, some limitations still exist in the integration of the BIM and VE area. Previous studies focused on small elements of the building or a phase of the VE study and used simulation to generate the results. There is a need, therefore, to conduct more empirical studies based on a whole project to evaluate the integration between VE and BIM thoroughly. Figure 1 shows a proposed framework for the integration of VE and BIM in the different phases of a construction project.

The integrated approach of BIM and VE application used in this study includes the following processes: develop the BIM model, conduct clash detection, import cost data from the BIM model using pricing software, develop comprehensive weight and indices to calculate the value coefficient, determine building elements with the value coefficient less than 1, apply suggested solutions and recommendations to enhance cost and functionality, apply BIM virtual and simulation to test recommendations, and develop a construction site management plan for more effective cost control. Typically, a $3 \mathrm{D}$ visualization model of BIM is created during the design stage based on architectural, structural, mechanical, and electrical models. BIM can be used for the rapid preparation of construction drawings, 


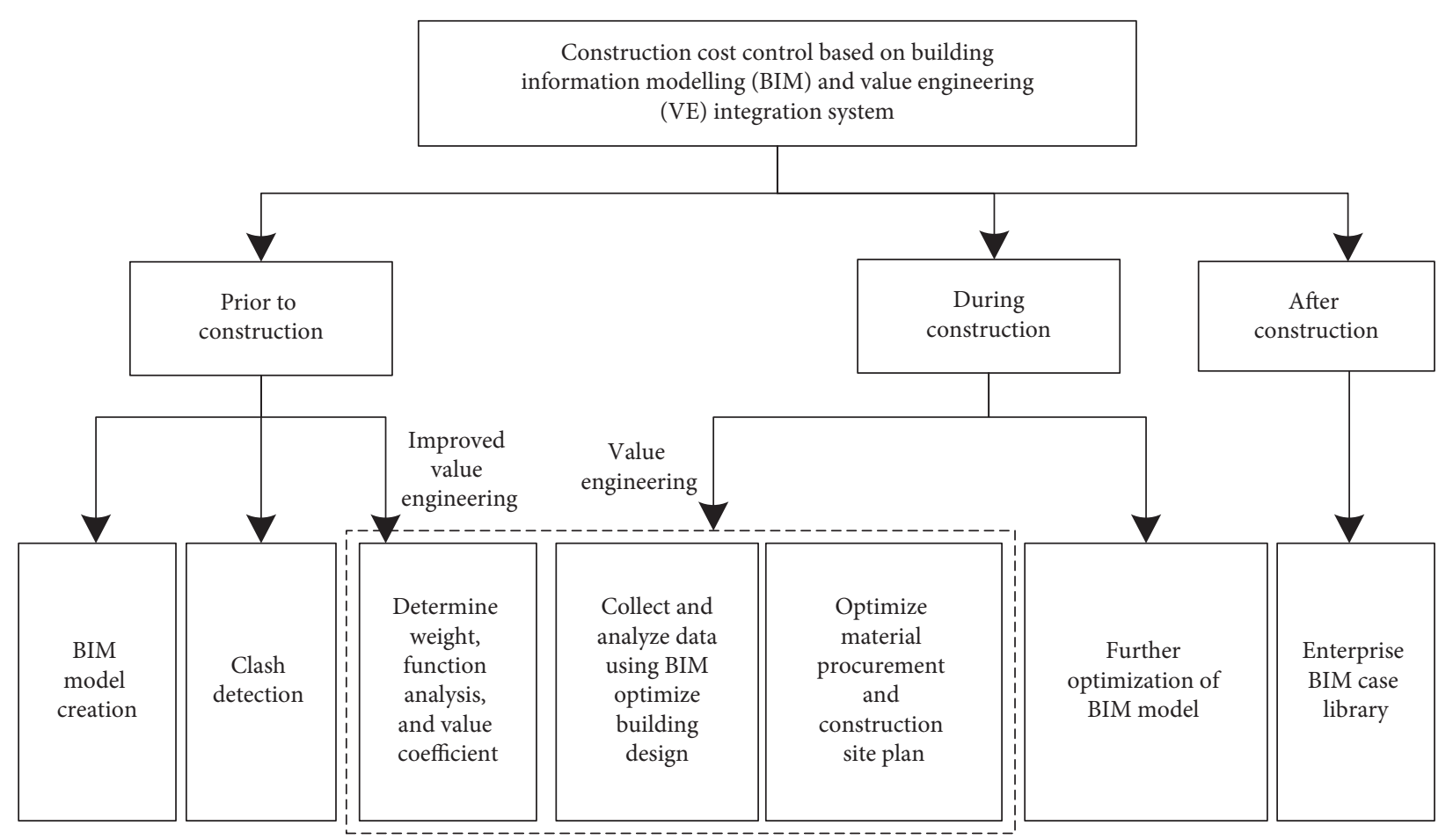

FIgURE 1: The construction cost control framework based on BIM and VE integration.

budget, project schedule, and resource allocation. The realtime updating of the model is convenient for all parties to communicate and meet the needs of the owner to the greatest extend. In this stage, clash detection and cost estimation can be performed before conducting VE analysis. BIM can also be used to virtually analyze the construction site plan.

This study puts forward the hypothesis that BIM enhances value engineering functions. The basic functions in BIM including visualization, function simulation, clash detection, and information integration are used to strengthen the function analysis of value engineering. The other advantages of using BIM such as quick extraction of information and real-time engineering changes are used to strengthen the cost analysis of the value study and subsequently enhance the performance of VE analysis.

\section{Research Methodology}

A case study method was used to develop the process of integrating BIM and VE. The application of BIM and VE in a high-rise building project in China was described and evaluated. The case study approach is suitable to describe certain processes or practices in their real context. More description of the case study project is provided in Section 5 . In this study, VE was used to identify high-cost elements, and BIM was used to detect clashes, develop cost information, and simulate the proposed changes to the design. An integral step involved in the improved value engineering method is to develop weight and project value indices using the analytic hierarchy process (AHP) and the entropy method, as shown in Figure 2. The selection of building elements to be evaluated was conducted by decomposing the building components into elements based on the hierarchical analysis of the project. The new method is validated throughout the case study.

During the construction stage and before procurement initiation, VE can be used to select the appropriate construction materials as well as developing a construction site management plan. VE can be applied directly before the construction stage to analyze building components, develop functional analysis, and determine the weightage to evaluate the building elements. The typical steps involved in the VE methodology application include establishing the VE team, conducting a functional analysis, determining weights through expert scoring and grade scoring methods, calculate function, cost, and value indices, develop alternatives and evaluate alternatives, and develop recommendations and countermeasures to improve cost and functionality of building elements. The following sections describe the development of VE indices. The framework developed in this study (refer to Figure 3) shows the integration between BIM and VE through an improved value engineering method.

3.1. Project Value Index. The first step in evaluating the cost of building components is to determine its value, which can be simply calculated as the ratio between the functional cost and the predetermined cost. The evaluation index of building elements can be evaluated and scored to obtain the total function score $F_{i}$ by using the weighted sum of all components of the building element or system. The function coefficient $\mathrm{FI}_{i}$ can be calculated using 


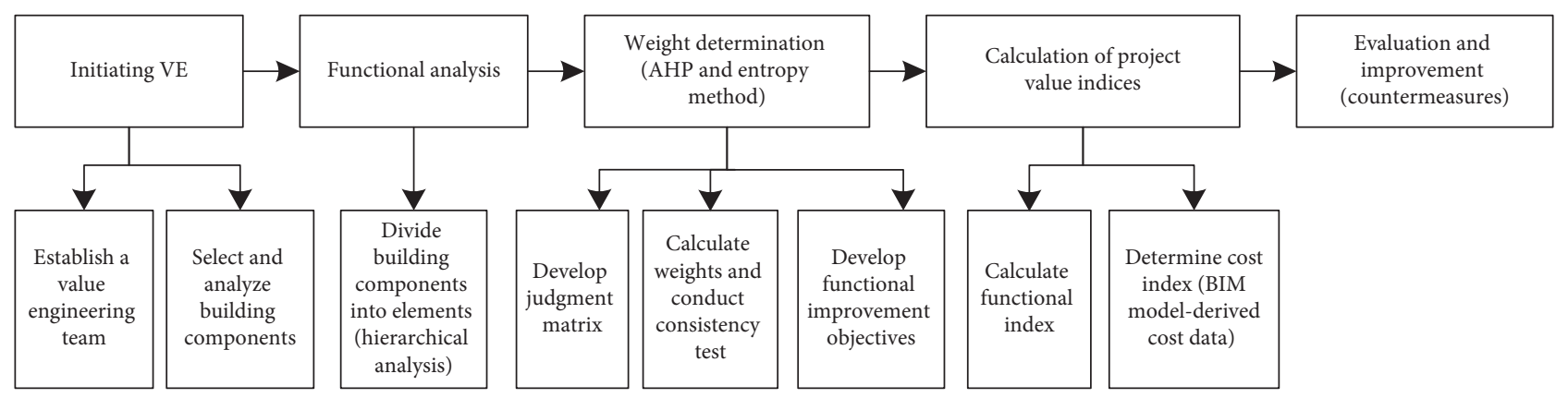

FIGURE 2: Improved value engineering processes.

$$
\mathrm{FI}_{i}=\frac{F_{i}}{\sum_{i=1}^{n} F_{i}}=\frac{\sum_{k=1}^{n} u_{i k} W_{k}}{\sum_{i=1}^{n}\left(\sum_{k=1}^{n} u_{i k} W_{k}\right)}, \quad i=1,2, \ldots, n,
$$

where $u_{i k}$ is the scores of each evaluation element, $W_{k}$ is the weight of each index, and $n$ is the number of factors of the index system.

The cost coefficient can be calculated based on the cost in the original BIM model based on building quantities. Equation (2) can be used to calculate the construction cost coefficient $\mathrm{CI}_{i}$ :

$$
\mathrm{CI}_{i}=\frac{C_{i}}{\sum_{i=1}^{n} C_{i}}, \quad i=1,2, \ldots, n .
$$

Subsequently, the value coefficient $\left(V_{i}\right)$ can be calculated as the ratio of the functional coefficient to the cost factor, as shown in

$$
V_{i}=\frac{\mathrm{FI}_{i}}{\mathrm{CI}_{i}}, \quad i=1,2, \ldots, n .
$$

If $V \geq 1$, the functional cost (i.e., worth) of the building element or system is equal or greater than the budget cost, which means that the cost of a particular element meets the requirements without the need for further adjustment such as redesign. However, if $V<1$, the cost standard of the target cost control object is less than the budget cost, and therefore, measures should be taken to control the cost of the element.

3.2. Weight Determination of the Functional Index. The analytic hierarchy process (AHP) and the entropy method are combined in this study to determine the subjective and objective weight of functional analysis and scoring of building elements. The AHP was developed by Saaty during the 1970s as a multicriteria decision-making tool [22]. The AHP has several applications in planning, resource allocation, and conflict resolution as it considers both deductive and inductive thinking taking several factors into account in the decision-making process [23]. The AHP has been widely used in various industries and fields, due to its strong ability to simplify complex problems. Therefore, this study uses the AHP to determine the importance of building elements for VE based on experts' opinions. Since the weights obtained by the AHP are subjective, and to obtain more accurate and objective evaluation results, the entropy weight method is introduced to obtain the objective weights in the evaluation index system. The entropy weight method uses information entropy to calculate the entropy weight of each indicator according to the degree of variation of each indicator and then corrects the weight of each indicator through entropy weight to obtain a more objective functional indicator weight. The processes used to develop the functional evaluation index are described as follows.

The first process is to develop the judgment matrix by establishing a hierarchical structure. For this purpose, a scale of 1 to 9 was used to represent experts' opinions regarding which alternative element or system to choose. The scale is shown in Table 1. The judgment matrix can be calculated by taking the average of experts' scores.

The second process was to calculate the maximum eigenvalue and eigenvector of the judgment matrix using the following steps. The product $A_{i}$ of each row element of the matrix is calculated in

$$
A_{i}=\prod_{j=1}^{n} a_{i j}, \quad i=1,2, \ldots, n .
$$

For $A_{i}$ to open the $n$th power root, the calculation is through

$$
\overline{W_{i}}=\sqrt[n]{A_{i}}, \quad i=1,2, \ldots, n
$$

Normalize the vector $\bar{W}=\left[\bar{W}_{1}, \bar{W}_{2}, \ldots, \bar{W}_{n}\right]^{T}$ in

$$
W_{i}=\frac{\overline{W_{i}}}{\sum_{j=1}^{n} \overline{W_{j}}}, \quad i=1,2, \ldots, n .
$$

The feature vector $W=\left(W_{1}, W_{2}, \ldots, W_{n}\right)^{T}$ and the weight vector of $A_{i}$ is relative to $A$. Calculating the maximum eigenvalue of the judgment matrix, $\lambda_{\max }$ in Equation (7) is given as follows:

$$
\lambda_{\max }=\sum_{i=1}^{n} \frac{(A W)_{i}}{n W_{i}}, \quad i=1,2, \ldots, n .
$$

The third process was to determine the consistency of the judgment matrix using the CI index using 


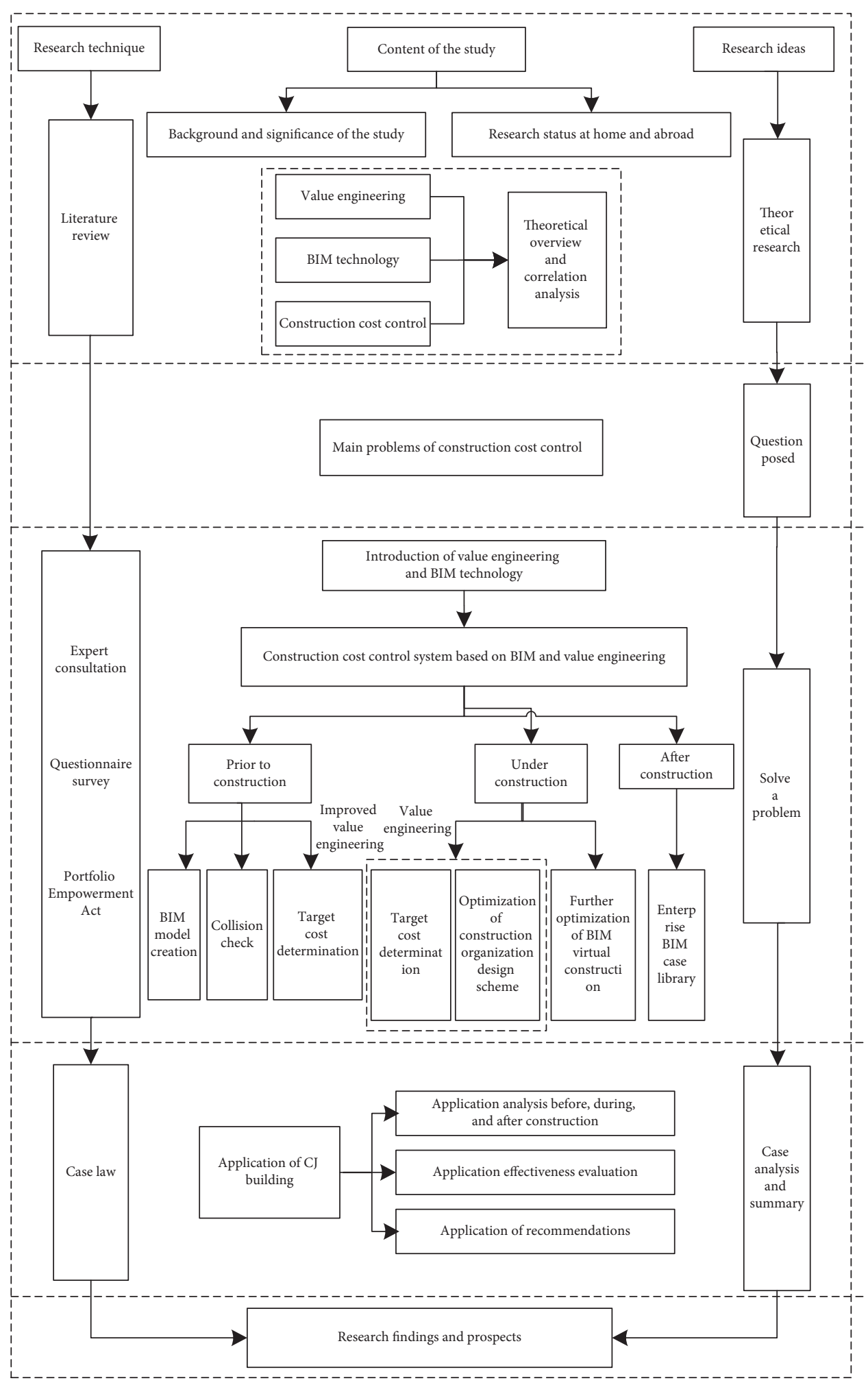

FIgURE 3: The research framework.

$\mathrm{CI}=\frac{\lambda_{\max }-n}{n-1}, \quad(N$ is the order of judgment matrix $)$.
The smaller the CI calculated, the higher the consistency of matrix $A$. If $C I=0$, then use the random index $C R$ to assist detection through 
Table 1: Scale values used in the judgment matrix of the AHP.

\begin{tabular}{lr}
\hline Scale & Meaning \\
\hline 1 & The two comparative factors $i$ and $j$ are of the same importance \\
5 & $i$ factor is slightly more important than $j$ factor \\
7 & $i$ factor is obviously more important than $j$ factor \\
9 & $i$ factor is strongly more important than $j$ factor \\
$2,4,6,8$ & $i$ factor is extremely more important than $j$ factor \\
Reciprocal & $a_{i j}$ represents the importance ratio of factor $i$ to factor $j$, and $a_{j i}=1 / a_{i j}$, which shows the importance ratio of factor $j$ to factor $i$
\end{tabular}

$$
\mathrm{CR}=\frac{\mathrm{CI}}{\mathrm{RI}}
$$

RI is the average consistency index, and some RI values are calculated in Table 2.

When $n=1,2$ and $\mathrm{RI}=0$, the formula was not valid, but when $\mathrm{CI}=0$, the formula was valid. When the order $n>2$, the formula holds. When $\mathrm{CR}=(\mathrm{CI} / \mathrm{RI})<0$, the matrix met the requirements. According to the hierarchy model layer, the consistency test of the total sorting is carried out in

$$
\mathrm{CR}=\frac{\sum B_{i} \mathrm{CI}_{i}}{\sum B_{I} \mathrm{RI}_{i}}, \quad i=1,2, \ldots, n,
$$

where $B_{i}$ is the weight value of each low level. When $\mathrm{CR}<0.1$, it means that the consistency requirements are met.

The fourth process was to determine the objective weight using the entropy weight method. This process included the following steps:

(a) Develop the original data matrix.. There are currently $m$ evaluation objects, and each evaluation object has $n$ evaluation indexes. The feedback data collected will be sorted to form the original data $R$ matrix, $R=\left(r_{i j}\right)_{m \times n}$.

(b) Normalize the original data matrix $R$, and calculate the proportion $P_{i j}$ of the index value of the $i$ object under the $j$ index as in

$$
P_{i j}=\frac{r_{i j}}{\sum_{i=1}^{m} r_{i j}}, \quad i=1,2, \ldots, m, j=1,2, \ldots, n .
$$

(c) Determine the entropy value of the $j$ index according to the entropy principle $e_{j}$ in

$$
e_{j}=-K \sum_{i=1}^{m} P_{i j} \cdot \ln P_{i j}, \quad i=1,2, \ldots, m, j=1,2, \ldots, n .
$$

Here, $K=1 / \ln m, e_{j} \in(0,1)$, and $P_{i j}=0, P_{i j} \ln$ $P_{i j}=0$

(d) Calculate the entropy weight of the $j$ index $w_{j}$ in

$$
\begin{aligned}
w_{j} & =\frac{1-e_{j}}{n-\sum_{j=1}^{n} e_{j}}, \\
\sum_{j=1}^{n} w_{j} & =1, \quad j=1,2, \ldots, n,
\end{aligned}
$$

where $w=\left(w_{1}, w_{2}, \ldots, w_{n}\right)$ is the entropy weight of the evaluation index.

The last process was to combine the AHP and entropy weight methods to take advantage of both methods and produce more accurate results. The combined weight $T$ is calculated in

$$
T=\frac{W_{j} \cdot w_{j}}{\sum_{j=1}^{n} W_{j} \cdot w_{j}},
$$

where $T$ is the combined weight determined by the AHP and entropy weight method, $W_{j}$ is the subjective weight calculated by the AHP, and $w_{j}$ is the objective weight calculated by the entropy weight method. Finally, the comprehensive weight was obtained: $T=\left(t, t_{2}, t_{3}, \ldots, t_{n}\right)$.

\section{Application of the Integrated Approach in the Case Study}

The case study of this research is a high-rise residential building called CJ building in Fujian Province, China. Figure 4 shows the $3 \mathrm{D}$ model of the building. The total land area of the project is $3076.93 \mathrm{~m}^{2}$, and the total building area is $44925.89 \mathrm{~m}^{2}$. The project included basement floors with a total area of $14570.70 \mathrm{~m}^{2}$. The main structural element of the building is the frame shear wall, with the ability to resist a 7 level earthquake. The design service life is 50 years with a fire resistance rating of Grade I for the underground and Grade II above the ground.

As the project is a high-rise building which has a large basement area, a lot of resources such as human, material, and machinery are consumed, a large number of processes are connected, the pipeline is densely arranged, and the ventilation, water supply, and drainage pipelines are complicated. The construction organization needs to be carefully determined, and coordinated construction requires scientific overall planning. Thus, the project is very suitable to use the construction cost control model based on BIM and value engineering.

4.1. BIM Application. Revit was used to complete the architectural, structural, mechanical, and electrical BIM models (Figure 5). The BIM model was also used to generate cost data including bill of quantities. The integration of the models and clash detection was performed using Navisworks. Clash detection was a significant process to ensure proper integration of different building elements and 
TABLE 2: The average consistency index, RI index value.

\begin{tabular}{lccccccccccc}
\hline Order number & 1 & 2 & 3 & 4 & 5 & 6 & 7 & 8 & 9 & 10 & $\ldots$ \\
\hline RI & 0.00 & 0.00 & 0.58 & 0.90 & 1.12 & 1.24 & 1.32 & 1.41 & 1.45 & 1.49 & $\ldots$ \\
\hline
\end{tabular}

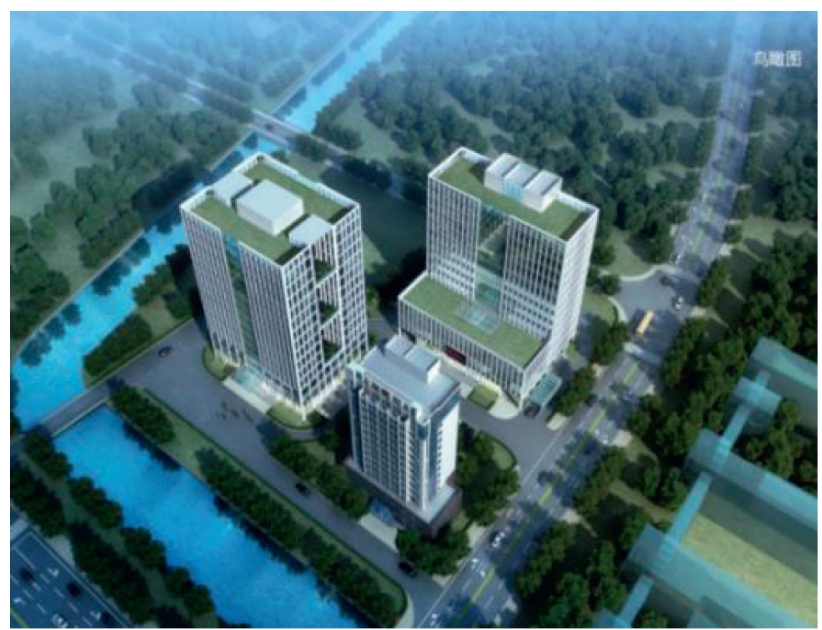

FIgURE 4: The case study project for the "CJ building."
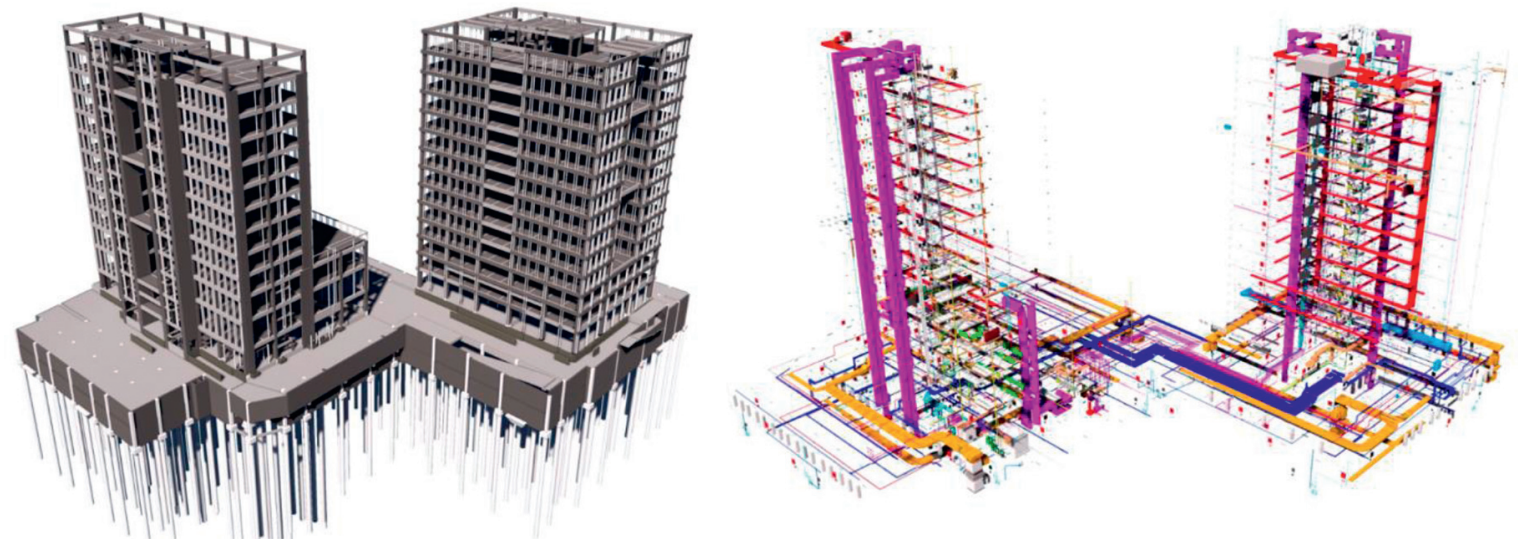

FIGURE 5: BIM structural, mechanical, electrical, and service models.

systems and less rework during the construction stage. This function could save a considerable amount of project time and cost. After completing the pipeline clash detection, according to the specifications, construction sequence, and avoidance principles, the existing clash is optimized and adjusted reasonably. Figure 6 shows an example of clash detection. In this project, 1821 clashes were found. The rectification of these clashes saved about 80 days of project time and RMB 603,918 (equivalent to about USD 87,700) of project direct cost. To solve the problems of the tight project schedule, difficult on-site section layout, limitation of material transportation times, and secondary handling of large machinery, this study also used the BIM model to rationally arrange the construction site and prepare the general layout of the construction site in advance. Figure 7 shows the project site planning simulation.

4.2. Function Analysis and Weight Determination. VE workshop was conducted to analyze factors that influence cost and ensure high value for building elements. The VE workshop included the following members: project manager, project technical director, value engineering experts, cost engineer, architect, structural engineer, and civil engineer. In the review analysis, the work breakdown structure (WBS) of the project was developed to obtain project deliverables, processes, and activities. The WBS enabled a better idea of the installation process, material inspection 


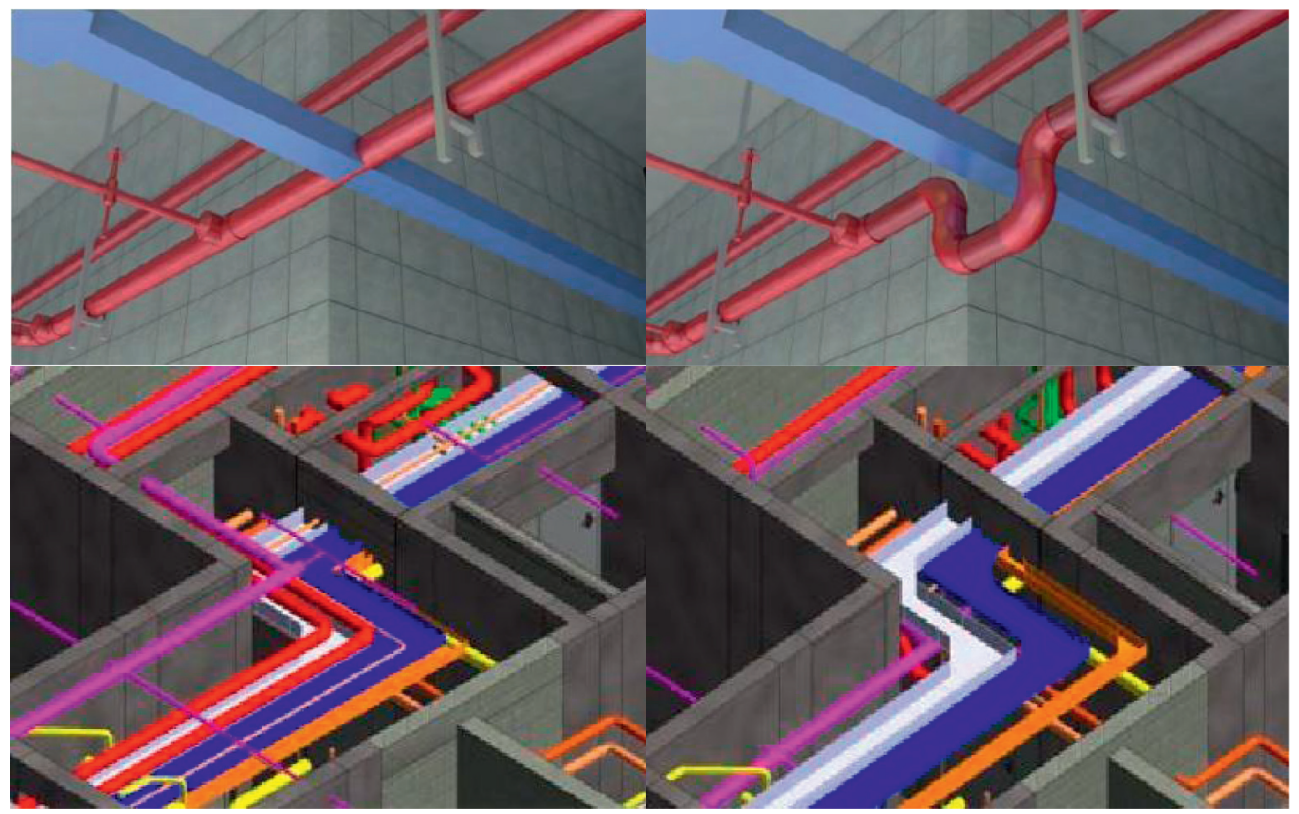

FIgURE 6: Clash detection and correction using BIM.

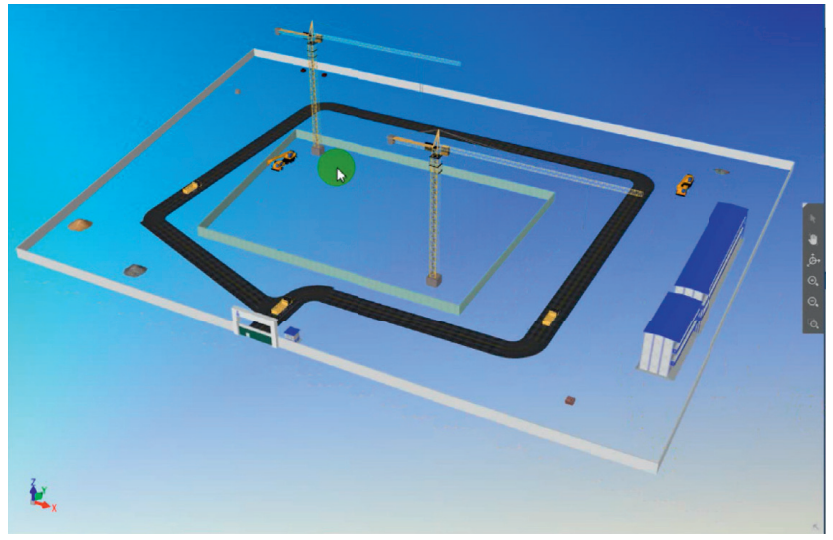

FIGURE 7: Project site planning simulation.

and test required, and others. Table 3 shows the hierarchical cost of building components and elements and percentages of the cost. The highest components in terms of cost were the structural, followed by services, installation, and finishes.

\section{Results}

5.1. Judgment Matrix and Components' Weights. In the AHP method, the scores were collected from each expert in the team, and the average score was calculated. The final optimal relationship matrix was developed, and then, the AHP was used to calculate the eigenvector $W$ and the maximum eigenvalue. The last step was to carry out the consistency test. In the three-level hierarchical structure model, the target layer is the CJ building construction project, and the criterion layer is structural work, services, installation work, and finishes' work. The project judgment matrix and weight calculation for each component are shown in Tables 4-7.
5.2. Entropy Weight Results. A structured interview survey targeting relevant experts was conducted. The questionnaire attempted to provide information on the importance index based on a scale of 1 to 9 . In total, 20 interviewees participated, and 11 participants were males and 9 were females. All the participants have extensive experience in construction in different areas including civil engineering, architecture, project management, quantity surveying, and other professions. $65 \%$ of the participants have between 10 and 20 years of experience, and $35 \%$ of them have between 20 and 30 years of experience. To calculate the objective weight using the entropy method, equation (12) was used to find the value of $e_{j}$ of each element. After that, the entropy weight $w_{j}$ of each element was calculated using equation (13), and the results are shown in Table 8. By combining subjective weight $W$ and objective weight $w$, the comprehensive weight can be calculated from equation (14), as shown in Table 9. 
TABLE 3: Cost of components and elements of the CJ building in ten thousand RMB (USD).

\begin{tabular}{|c|c|c|c|c|c|}
\hline Building components & Name of element & $\begin{array}{c}\text { Abbreviation of } \\
\text { elements }\end{array}$ & $\begin{array}{l}\text { Cost of } \\
\text { element }\end{array}$ & $\begin{array}{c}\text { Cost of } \\
\text { components }\end{array}$ & $\begin{array}{l}\text { Percentage of cost } \\
(\%)\end{array}$ \\
\hline \multirow{5}{*}{ Structural (A1) } & Steel and concrete works & A11 & $\begin{array}{l}3895.64 \\
(573.36)\end{array}$ & \multirow{5}{*}{$7766.46(1143.07)$} & \multirow{5}{*}{55} \\
\hline & $\begin{array}{l}\text { Basement and underground } \\
\text { works }\end{array}$ & A12 & $\begin{array}{l}1823.02 \\
(268.31)\end{array}$ & & \\
\hline & & & 1041.38 & & \\
\hline & Masonry works & A13 & $(153.27)$ & & \\
\hline & Floor work & A14 & $\begin{array}{l}1006.42 \\
(148.12)\end{array}$ & & \\
\hline \multirow{3}{*}{$\begin{array}{l}\text { Services and } \\
\text { installations (A2) }\end{array}$} & $\begin{array}{l}\text { Hydropower, HVAC, and fire } \\
\text { protection }\end{array}$ & A21 & $\begin{array}{l}1794.71 \\
(264.15)\end{array}$ & \multirow{3}{*}{$3069.31(451.74)$} & \multirow{3}{*}{21.8} \\
\hline & Elevator works & $\mathrm{A} 22$ & $\begin{array}{l}250.68 \\
(36.90)\end{array}$ & & \\
\hline & Doors and windows & A23 & $129.78(19.10)$ & & \\
\hline \multirow{3}{*}{ Finishes (A3) } & Wall decoration works & A31 & $\begin{array}{c}1568.2 \\
(230.81)\end{array}$ & \multirow{3}{*}{$2175.17(320.14)$} & \multirow{3}{*}{15.4} \\
\hline & Coating insulation works & A32 & $\begin{array}{l}1294.74 \\
(190.56)\end{array}$ & & \\
\hline & Ceiling decoration works & A33 & $\begin{array}{l}206.37 \\
(30.37)\end{array}$ & & \\
\hline Others & & - & $\begin{array}{l}1100.01 \\
(161.90)\end{array}$ & $1100.01(161.90)$ & 7.8 \\
\hline Total & & & & $\begin{array}{l}14110.95 \\
(2049.22)\end{array}$ & 100 \\
\hline
\end{tabular}

TABLE 4: Judgment matrix $(A)$ and weight calculation of the CJ building construction project.

\begin{tabular}{lcccc}
\hline CJ building project A & Structural works A1 & Services and installation works A2 & Finishes' works A3 & Weight $W_{i}$ \\
\hline Structural works A1 & 1 & 7 & 8 & 0.7766 \\
Services and installation works A2 & $1 / 7$ & 1 & 3 & 0.1530 \\
Finishes works A3 & $1 / 8$ & $1 / 3$ & 1 & 0.0704 \\
$\lambda_{\max }=3.1044, \mathrm{CI}=0.0522, \mathrm{RI}=0.58$, and CR $=0.0900$ & & \\
\hline
\end{tabular}

TABLE 5: The weight calculation matrix for structural works (A1).

\begin{tabular}{|c|c|c|c|c|c|}
\hline Structural works A1 & $\begin{array}{l}\text { Reinforcement and concrete } \\
\text { works A11 }\end{array}$ & $\begin{array}{l}\text { Underground basement } \\
\text { works A12 }\end{array}$ & $\begin{array}{l}\text { Masonry works } \\
\text { A13 } \\
\end{array}$ & $\begin{array}{c}\text { Floor works } \\
\text { A14 }\end{array}$ & $\begin{array}{c}\text { Weight } \\
W_{i}\end{array}$ \\
\hline $\begin{array}{l}\text { Reinforcement and concrete } \\
\text { works A11 }\end{array}$ & 1 & 7 & 6 & 7 & 0.6705 \\
\hline $\begin{array}{l}\text { Underground basement works } \\
\text { A12 }\end{array}$ & $1 / 7$ & 1 & 3 & 3 & 0.1724 \\
\hline Masonry works A13 & $1 / 6$ & $1 / 3$ & 1 & 2 & 0.0935 \\
\hline Floor works A14 & $1 / 7$ & $1 / 3$ & $1 / 2$ & 1 & 0.0636 \\
\hline \multicolumn{6}{|c|}{$\lambda_{\max }=4.2262, \mathrm{CI}=0.0754, \mathrm{RI}=0.9$, and $\mathrm{CR}=0.0838$} \\
\hline
\end{tabular}

After calculating the comprehensive weights, the next process is to determine the cost factor based on VE workshop outcomes. The steps involved in this process include determine the bill of quantities using the BIM model, generate the cost data based on the amended model, determine the value coefficient, and develop improvement measures and evaluation. In the first step, the bill of quantities of the building is extracted from the BIM model by importing the model into the GCL software through GFC plug-in in Revit. The bill of quantities was then imported into GBQ software to calculate the total cost. The unit price is adjusted according to the market price based on human resources, material, and machinery costs. The cost information of the building is shown in Table 3. The value coefficient was then calculated based on the cost data. The result is shown in Table 10. Value coefficient results show building elements that need further improvement with regard to cost control. Elements with a value coefficient less than 1 include steel and concrete works, underground basement, masonry works, floor works, and coating insulation works. These elements were considered for further analysis to achieve better value and cost control. 
TABLE 6: The weight calculation matrix for services and installation works (A2).

\begin{tabular}{|c|c|c|c|c|}
\hline Services and installation A2 & $\begin{array}{c}\text { Hydropower, HVAC, and fire protection } \\
\text { works A21 }\end{array}$ & $\begin{array}{l}\text { Elevator works } \\
\text { A22 }\end{array}$ & $\begin{array}{l}\text { Doors and windows } \\
\text { A23 }\end{array}$ & $\begin{array}{c}\text { Weights } \\
W_{i}\end{array}$ \\
\hline $\begin{array}{l}\text { Hydropower, HVAC, and fire protection } \\
\text { works A21 }\end{array}$ & 1 & 3 & 6 & 0.6348 \\
\hline Elevator works A22 & $1 / 3$ & 1 & 5 & 0.2872 \\
\hline $\begin{array}{l}\text { Doors and windows } \mathrm{A} 23 \\
\lambda_{\max }=3.0940, \mathrm{CI}=0.0470, \mathrm{RI}=0.58 \text {, an }\end{array}$ & $\mathrm{d} C R=0.0810$ & $1 / 5$ & 1 & 0.0780 \\
\hline
\end{tabular}

TABle 7: The weight calculation matrix for finishes (A3).

\begin{tabular}{lcccc}
\hline Finishes' works A3 & Wall decoration A31 & Coating insulation A32 & Ceiling decoration A33 & Weights $W_{i}$ \\
\hline Wall decoration A31 & 1 & 4 & 8 & 0.6986 \\
Coating insulation A32 & $1 / 4$ & 1 & 5 & 0.2370 \\
Ceiling decoration A33 & $1 / 8$ & $1 / 5$ & 1 & 0.0643 \\
$\lambda_{\max }=3.0940, \mathrm{CI}=0.0470, \mathrm{RI}=0.58$, and CR $=0.0810$ & & & \\
\hline
\end{tabular}

TABLE 8: The entropy weight table to calculate the objective weight.

\begin{tabular}{|c|c|c|c|c|c|c|c|c|c|c|}
\hline & \multicolumn{4}{|c|}{ Structural work (A1) } & \multicolumn{3}{|c|}{ Services and installation (A2) } & \multicolumn{3}{|c|}{ Finishes (A3) } \\
\hline & A11 & A12 & A13 & A14 & $\mathrm{A} 21$ & A22 & $\mathrm{A} 23$ & A31 & A32 & A33 \\
\hline Expert 1 & 8 & 6 & 4 & 5 & 6 & 4 & 2 & 3 & 3 & 3 \\
\hline Expert 2 & 6 & 7 & 3 & 5 & 5 & 5 & 2 & 2 & 2 & 2 \\
\hline Expert 3 & 8 & 4 & 3 & 4 & 5 & 4 & 2 & 3 & 3 & 3 \\
\hline Expert 4 & 7 & 6 & 4 & 4 & 5 & 4 & 2 & 2 & 3 & 3 \\
\hline Expert 5 & 4 & 6 & 5 & 6 & 5 & 4 & 3 & 4 & 3 & 3 \\
\hline Expert 6 & 5 & 6 & 4 & 4 & 8 & 3 & 2 & 3 & 3 & 3 \\
\hline Expert 7 & 6 & 5 & 4 & 4 & 6 & 3 & 3 & 3 & 5 & 4 \\
\hline Expert 8 & 8 & 8 & 3 & 4 & 5 & 4 & 2 & 4 & 3 & 3 \\
\hline Expert 9 & 5 & 7 & 4 & 4 & 5 & 4 & 2 & 3 & 4 & 4 \\
\hline Expert 10 & 6 & 5 & 3 & 6 & 4 & 4 & 2 & 4 & 3 & 3 \\
\hline Expert 11 & 5 & 8 & 3 & 5 & 5 & 4 & 2 & 3 & 3 & 3 \\
\hline Expert 12 & 8 & 5 & 4 & 5 & 4 & 4 & 2 & 3 & 2 & 2 \\
\hline Expert 13 & 5 & 8 & 4 & 4 & 5 & 4 & 2 & 3 & 3 & 3 \\
\hline Expert 14 & 4 & 8 & 3 & 5 & 4 & 3 & 2 & 3 & 3 & 3 \\
\hline Expert 15 & 8 & 4 & 4 & 4 & 5 & 3 & 2 & 3 & 3 & 2 \\
\hline Expert 16 & 6 & 8 & 3 & 5 & 3 & 2 & 2 & 3 & 3 & 3 \\
\hline Expert 17 & 5 & 7 & 3 & 4 & 4 & 5 & 2 & 2 & 3 & 3 \\
\hline Expert 18 & 8 & 6 & 4 & 3 & 5 & 4 & 1 & 3 & 3 & 4 \\
\hline Expert 19 & 5 & 4 & 4 & 3 & 5 & 5 & 2 & 2 & 3 & 3 \\
\hline Expert 20 & 9 & 5 & 2 & 6 & 4 & 3 & 2 & 3 & 3 & 3 \\
\hline Entropy $e_{j}$ & 0.9903 & 0.9913 & 0.9939 & 0.9938 & 0.9934 & 0.9932 & 0.9941 & 0.9932 & 0.9941 & 0.9943 \\
\hline Entropy weight $w_{j}$ & 0.1425 & 0.1269 & 0.0894 & 0.0904 & 0.0963 & 0.0993 & 0.0867 & 0.0994 & 0.0861 & 0.0830 \\
\hline
\end{tabular}

VE team members and other relevant professionals in the project analyzed and discussed cost control measures of the selected elements. The causes of the additional cost of each element and strategies were developed to enhance the value of the whole project. As a result of the application of the integrated approach of BIM and VE, the overall cost of the project was reduced by approximately $10 \%$, as shown in Table 11.

\section{Discussion and Recommendations}

The practical procedures to enhance the project value, to reduce the completion time, and to enhance the overall quality of the project were identified based on the result of this study. The integrated approach of BIM and VE has proven effective in enhancing the project value and control project cost. The current study presents the following recommendations as a lesson-learned set realized as a result of conducting this case study. The recommendations provide practical steps to enhance the project value, reduce the completion time, and enhance the overall quality of the project. Although it is difficult to generalize the result from a single case study, the following recommendations can serve as a general guideline for other building projects to enhance value and performance using the BIM and VE-integrated approach.

First, the causes of the high cost of building elements were identified. The reinforcement handling process, 
TABLE 9: Comprehensive weight calculation results.

\begin{tabular}{lccc}
\hline Indicators & Subjective weight $W$ & Objective weight $w$ & Comprehensive weights $T$ \\
\hline Steel and concrete A11 & 0.6705 & 0.1425 & 0.2957 \\
Underground basement A12 & 0.1724 & 0.1269 & 0.0677 \\
Masonry works A13 & 0.0935 & 0.0894 & 0.0259 \\
Floor works A14 & 0.0636 & 0.0904 & 0.0178 \\
Water, HVAC, and fire protection A21 & 0.6348 & 0.0963 & 0.1892 \\
Elevator works A22 & 0.2872 & 0.0993 & 0.0882 \\
Doors and windows A23 & 0.0780 & 0.0867 & 0.0209 \\
Wall decoration A31 & 0.6986 & 0.0994 & 0.2149 \\
Coating insulation A32 & 0.2370 & 0.0861 & 0.0632 \\
Ceiling decoration A33 & 0.0643 & 0.0830 & 0.0165 \\
\hline
\end{tabular}

TABLE 10: Value coefficient calculation table of the CJ building construction project.

\begin{tabular}{|c|c|c|c|c|c|c|}
\hline Components & Elements & $\begin{array}{l}\text { Function coefficient } \\
\text { (F) }\end{array}$ & $\begin{array}{c}\text { Cost (ten thousand } \\
\text { RMB) }\end{array}$ & $\begin{array}{c}\text { Cost factor } \\
(\mathrm{C})\end{array}$ & $\begin{array}{l}\text { Value coefficient } \\
\text { (c) }\end{array}$ & $\begin{array}{c}\text { Need } \\
\text { improvement }\end{array}$ \\
\hline \multirow{4}{*}{ Structural works (A1) } & A11 & 0.2957 & 3895.64 & 0.2994 & 0.9876 & $\checkmark$ \\
\hline & $\mathrm{A} 12$ & 0.0677 & 1823.02 & 0.1401 & 0.4832 & $\checkmark$ \\
\hline & A13 & 0.0259 & 1041.38 & 0.0800 & 0.3236 & $\checkmark$ \\
\hline & A14 & 0.0178 & 1006.42 & 0.0774 & 0.2301 & $\checkmark$ \\
\hline \multirow{3}{*}{$\begin{array}{l}\text { Services and installation } \\
\text { works (A2) }\end{array}$} & A21 & 0.1892 & 1794.71 & 0.1379 & 1.5579 & - \\
\hline & A22 & 0.0883 & 250.68 & 0.0193 & 3.2802 & - \\
\hline & A23 & 0.0209 & 129.78 & 0.0100 & 1.6542 & - \\
\hline \multirow{3}{*}{ Finishes' works (A3) } & A31 & 0.2149 & 1568.2 & 0.1205 & 1.5697 & - \\
\hline & A32 & 0.0632 & 1294.74 & 0.0995 & 0.8863 & $\checkmark$ \\
\hline & A33 & 0.0165 & 206.37 & 0.0159 & 1.3177 & - \\
\hline All combined & & 1 & 13010.94 & 1 & & \\
\hline
\end{tabular}

TABLE 11: Potential cost saving as a result of VE and BIM application in ten thousand RMB (USD).

\begin{tabular}{lccr}
\hline Building components & Original cost & Cost after VE and BIM & Difference \\
\hline Civil engineering & $7766.46(1143.07)$ & $6575.20(967.74)$ & $1191.26(175.33)$ \\
Installation project & $3069.31(451.74)$ & $3069.31(451.74)$ & 0 \\
Decoration engineering & $2175.17(320.14)$ & $1865.82(274.61)$ & $309.35(45.53)$ \\
Total & $13010.94(1914.95)$ & $11510.33(1694.09)$ & $1500.61(220.86)$ \\
\hline
\end{tabular}

rework, quality of steel bars, and low strength of concrete are the major contributors to material waste. In view of these problems, the following measures were identified: (a) strict control of reinforcement and concrete materials by the procurement department during the construction stage; (b) optimize reinforcement and steel bar design to reduce waste; (c) proper handling of leftover materials and adopt waste management across the project; (d) strict control of concrete grades according to the design; (e) consider concrete mixtures to improve the strength and performance of concrete and reduce the maintenance cost. In this case study, the VE team developed a weighted evaluation matrix of different steel suppliers to choose the best supplier by evaluating different preset criteria including quality, price, transportation fee, and reputation. The index weights for all the suppliers were included in a sheet, and the best supplier was selected based on the highest score. The result of this exercise is not shown here for the sake of brevity.

Second, the reasons for the high cost for the underground works are identified which include labor cost, material cost increase, long duration to complete the underground work, amount of excavation work, improper project management organization of this work, and high amount of construction waste. Measures to be undertaken to control the cost of the basement and underground work were identified as follows: (a) control of labor cost and management; (b) improve labor productivity; (c) control the thickness of the overburden; (d) improve the overall construction management for this phase such as optimizing resource allocation, using new technology, and reducing the time required to complete this work. The VE evaluated four alternatives of the project program using the weighted evaluation matrix and selected the best alternative based on value coefficient results and BIM simulation. The criteria used in the matrix are construction safety, time, quality, and economic benefits. The result of this exercise was not presented here for the sake of brevity.

Third, the reasons for the extra cost involved in the masonry works were identified, including changes to the drawings, construction waste material, arbitrary brick cutting, and incomplete construction site clearance. The following strategies were determined: (a) ensure timely and 
appropriate change management; (b) improve construction site management; (c) implement material quota. BIM was used to simulate and optimize the site layout of the project (refer to Figure 7). The temporary facilities, construction machinery and equipment, roads, storage areas, and other components of the site were visualized and reasonably arranged prior to the construction. This exercise facilitated detection issues, developing a better understanding of the project process, reducing risk and hazards, and methods of dealing with building materials and large machinery in the site. A similar simulation was conducted within the building to check clashes, develop a better understanding of construction activities and processes, and check the safety and if there was an issue that has been overlooked.

Fourth, the issues contributing to the high cost of building floor works included construction machinery causing idle time and lack of awareness of construction workers regarding wasted materials. The following measures were identified: (a) optimize resources including human and machinery resources; (b) improve the management of machinery and equipment on-site; (c) improve the utilization rate of machinery; (d) improve workers' awareness of handling building materials and environmental protection.

Last, the reasons for the high cost of coating insulation works included the initial high cost of materials, lack of skills of workers, and rework, and the following measures were identified: (a) improve material management; (b) control the initial cost of the coating material via proper procurement; (c) improve construction technology management; (d) improve workers' skills and project overall quality; (e) ensure the appropriate sequence of activities to avoid clashes and reduce rework.

\section{Conclusion}

In this study, BIM and VE are introduced to control and manage project cost using a case study. The analytics hierarchy process and entropy weight methods proved to be effective during the application of VE to determine value coefficients. The improved VE method using the AHP and entropy method suggested in this paper provided a comprehensive and yet easy approach to develop comprehensive weight determination of the function of building components. Besides, this study demonstrated how the integration of BIM and VE facilitates cost control and enhanced the functionality and performance of the project. The benefits of the integrated approach developed in this paper include fast and more accurate analysis of cost and function information, quick decision-making process, straightforward analysis of the impact of changes on the building design, and ease of developing recommendations and countermeasures to improve project cost, schedule, and quality. In particular, BIM facilitated the application and validation of ideas generated to enhance building design and construction. The advantages of integrating both approaches can be realized during the design, construction, and operation stages. During the design, BIM was used to detect clashes, and the 3D models facilitate understanding building components. BIM facilitated the generation of cost data such as the bill of quantities.
During the construction stage, this method facilitated the development of the material procurement plan and the construction site management plan. During the operation stage, the completion settlement was conducted quickly, and the enterprise-level BIM case database was established to provide a reference for the cost control of similar projects in the future. The integrated approach contributed to a $10 \%$ reduction in project time and cost and resulted in an easy and more efficient conduct of the value study.

The construction cost control framework based on the integration of BIM and VE proposed in this paper can significantly improve construction management, enhance the project value, and save the construction time, which can be used as a reference for construction companies to carry out cost control. The current study is not the first attempt to integrate BIM and VE. However, this study showed how the two concepts can be applied successfully in an actual case study project across different stages of the project. The findings of this study can provide a framework for construction companies to apply VE and improve the construction management process. Although the objectives of this study have been achieved, some limitations still exist. This study was based exclusively on the context of Fujian, China. Therefore, the results may vary in other countries or other types of construction projects. Future research can focus on real-time analysis of project schedule, safety, and quality, while implementing cost control changes.

\section{Data Availability}

All data generated or analyzed during this study are included within the article.

\section{Conflicts of Interest}

The authors declare that they have no conflicts of interest.

\section{References}

[1] H. C. J. Linderoth, "Understanding adoption and use of BIM as the creation of actor networks," Automation in Construction, vol. 19, no. 1, pp. 66-72, 2010.

[2] Z. Ma, H. Li, G. Q. Shen, and J. Yang, "Using XML to support information exchange in construction projects," Automation in Construction, vol. 13, no. 5, pp. 629-637, 2004.

[3] B. Huang, J. Lei, F. Ren et al., "Contribution and obstacle analysis of applying BIM in promoting green buildings," Journal of Cleaner Production, vol. 278, Article ID 123946, 2021.

[4] F. P. Rahimian, S. Seyedzadeh, S. Oliver, S. Rodriguez, and N. Dawood, "On-demand monitoring of construction projects through a game-like hybrid application of BIM and machine learning," Automation in Construction, vol. 110, Article ID 103012, 2020.

[5] A. Ravald and C. Grönroos, "The value concept and relationship marketing," European Journal of Marketing, vol. 30, no. 2, pp. 19-30, 1996.

[6] J. Schiff and A. L. Schiff, "Focusing on cost management during economic downturns," Financial Executive, vol. 24, no. 8, pp. 49-51, 2008. 
[7] Y. Wen, "Research on cost control of construction project based on the theory of lean construction and BIM: case study," The Open Construction and Building Technology Journal, vol. 8, no. 1, pp. 382-388, 2014.

[8] Y. Hong, A. W. A. Hammad, A. Akbarnezhad, and M. Arashpour, "A neural network approach to predicting the net costs associated with BIM adoption," Automation in Construction, vol. 119, Article ID 103306, 2020.

[9] J. Kelly, S. Male, and D. Graham, Value Management of Construction Projects, John Wiley \& Sons, Hoboken, NJ, USA, 2nd edition, 2015.

[10] R. S. Heralova, "Possibility of using value engineering in highway projects," Procedia Engineering, vol. 164, pp. 362367, 2016.

[11] R. Rachwan, I. Abotaleb, and M. Elgazouli, "The influence of value engineering and sustainability considerations on the project value," Procedia Environmental Sciences, vol. 34, pp. 431-438, 2016.

[12] C. Moreno, S. Olbina, and R. R. Issa, "BIM use by architecture, engineering, and construction (AEC) industry in educational facility projects," Advances in Civil Engineering, vol. 2019, Article ID 1392684, 19 pages, 2019.

[13] J. Choi, F. Leite, and D. P. de Oliveira, "BIM-based benchmarking for healthcare construction projects," Automation in Construction, vol. 119, Article ID 103347, 2020.

[14] B. C. Guerra, F. Leite, and K. M. Faust, "4D-BIM to enhance construction waste reuse and recycle planning: case studies on concrete and drywall waste streams," Waste Management, vol. 116, pp. 79-90, 2020.

[15] R. Matarneh and S. Hamed, "Barriers to the adoption of building information modeling in the Jordanian building industry," Open Journal of Civil Engineering, vol. 7, no. 3, pp. 325-335, 2017.

[16] M. Oraee, M. R. Hosseini, D. J. Edwards, H. Li, E. Papadonikolaki, and D. Cao, "Collaboration barriers in BIM-based construction networks: a conceptual model," International Journal of Project Management, vol. 37, no. 6, pp. 839-854, 2019.

[17] L. Deng, M. Zhong, L. Liao, L. Peng, and S. Lai, "Research on safety management application of dangerous sources in engineering construction based on BIM technology," Advances in Civil Engineering, vol. 2019, Article ID 7450426, 10 pages, 2019.

[18] Y. L. Yin and K. Qian, "Construction project cost management based on BIM technology," Applied Mechanics and Materials, vol. 357-360, pp. 2147-2152, 2013.

[19] T. Nath, M. Attarzadeh, R. L. K. Tiong, C. Chidambaram, and $\mathrm{Z}$. Yu, "Productivity improvement of precast shop drawings generation through BIM-based process re-engineering," Automation in Construction, vol. 54, pp. 54-68, 2015.

[20] T. Wei and Y. Chen, "Green building design based on BIM and value engineering," Journal of Ambient Intelligence and Humanized Computing, vol. 11, no. 9, pp. 3699-3706, 2019.

[21] C.-S. Park, H.-J. Kim, H.-T. Park, J.-H. Goh, and A. Pedro, "BIM-based idea bank for managing value engineering ideas," International Journal of Project Management, vol. 35, no. 4, pp. 699-713, 2017.

[22] T. L. Saaty, The Analytic Hierarchy Process, McGraw-Hill, New York, NY, USA, 1980.

[23] R. W. Saaty, "The analytic hierarchy process-what it is and how it is used," Mathematical Modelling, vol. 9, no. 3-5, pp. 161-176, 1987. 